\title{
Relações entre estratégias metacognitivas de leitura e desempenho escolar: possibilidades para o ensino de leitura
}

Relationships between metacognitive reading strategies and school performance: possibilities for teaching reading

\author{
Maria Clara Maciel de Araújo Ribeiro* \\ mclaramaciel@hotmail.com \\ https://orcid.org/0000-0001-9205-5858
}

\author{
Thiago Loyola Franco** (D) \\ thiagoloyola@yahoo.com.br \\ https://orcid.org/0000-0002-8729-590X
}

\author{
Anne Caroline Lima Campos ${ }^{* * *}$ (D) \\ annecarolinelima3214@gmail.com \\ https://orcid.org/0000-0003-3623-029X
}

\begin{abstract}
Resumo
Avaliações em larga escala indicam que ainda é preciso atuar em prol do desenvolvimento de habilidades de leitura no Brasil. Nesse contexto, o ensino de estratégias metacognitivas de leitura pode oferecer importantes contribuições. Assim, este estudo objetiva delinear quais são as relações entre a mobilização de estratégias metacognitivas de leitura e o desempenho escolar, sob uma perspectiva sociocognitiva. Para tanto, aplicou-se uma escala de estratégias de leitura a estudantes do Ensino Médio com alto e baixo desempenho escolar, comparandose os resultados. A pesquisa demonstra que estudantes com alto desempenho escolar utilizam-se de mais estratégias de leitura que alunos com baixo desempenho, o que corrobora o entendimento de que metacognição, leitura e desempenho escolar são fatores interrelacionados.
\end{abstract}

Palavras-chave: Proficiência leitora; Rendimento escolar; Metacognição; Estratégias de leitura; Ensino médio.

\footnotetext{
* Universidade Estadual de Montes Claros (Unimontes), Montes Claros, MG, Brasil.

** Universidade Estadual de Montes Claros (Unimontes), Montes Claros, MG, Brasil.

*** Universidade Estadual de Montes Claros (Unimontes), Montes Claros, MG, Brasil.
}

\section{LINHA DÁGUA}




\begin{abstract}
Large-scale evaluations indicate that it is still necessary to act in favor of the development of reading skills in Brazil. In this context, teaching metacognitive reading strategies can offer important contributions. Thus, this study aims to understand what are the observable correlations between the deployment of metacognitive reading strategies and school performance, from a sociocognitive perspective. To this end, a scale of reading strategies was applied to high school students ranging from low to high performance, comparing the results. The research showed that high performance students use more reading strategies than low performance students, a result that corroborates that metacognition, reading and school performance are interrelated factors.
\end{abstract}

Keywords: Reading proficiency; School performance; Metacognition; Reading strategies; High school.

\title{
Introdução
}

A escrita é uma tecnologia associada ao progresso das sociedades, haja vista que o conhecimento formal se estabelece e se difunde por ela. Habilidades de leitura, nesse contexto, se tornam essenciais para a apreensão do conhecimento e para a retroalimentação do sistema de saber, visto que a leitura de hoje se torna a base da escrita de amanhã.

Ler e escrever também servem, hoje, à interação cotidiana e à difusão de informação corriqueira. $\mathrm{O}$ avanço da tecnologia proporcionou informação imediata e veloz, tornando a interação instantânea e as nossas redes (neurais e sociais) cada vez mais amplas. Por um lado, tudo isso indica que, certamente, hoje estamos lendo mais, mas, por outro, não garante que estamos lendo melhor. Ao contrário, se levarmos em conta a leitura dinâmica e veloz que se processa em mídias sociais, teremos a impressão de que estamos lendo cada vez mais superficialmente.

Essa discussão interessa na medida em que, confrontando os índices de avaliações em larga escala, como o PISA ${ }^{1}$, com observações empíricas de práticas de leitura sociais atuais, nos vemos diante de uma aparente contradição: se as pessoas leem mais hoje, sobretudo devido à internet, porque índices de leitura como os do PISA não cresceram na mesma proporção?

Solé (1998) ilumina a questão quando explica que são os objetivos da leitura que determinam como se lê. Ler para aprender, como se faz na escola e na universidade, é substancialmente diferente de ler para se informar ou para interagir/dialogar, como se faz em redes sociais, por exemplo. Na escola, majoritariamente, a leitura serve à aprendizagem ou à demonstração de aprendizagem (quando se demonstra, por exemplo, a capacidade de interpretar textos), e é esse tipo de leitura que se afere nas avaliações de larga escala.

1 Dados do Programa Internacional de Avaliação de Estudantes (PISA) de 2018, promovido pela Organização para a Cooperação e Desenvolvimento Econômico (OCDE), apontam que "cerca de 50\% dos brasileiros não atingiram o mínimo de proficiência que todos os jovens devem adquirir até o final do Ensino Médio" (BRASIL, 2019). O programa também revela que apenas $0,2 \%$ dos 10.961 estudantes brasileiros participantes da pesquisa conseguiram alcançar o nível máximo de proficiência em leitura.

\section{LINHA D'́GUA}


Por esse prisma, parece que a leitura em redes sociais e afins ajuda pouco à leitura escolar, embora certamente ela não seja insignificante. O que estamos dizendo é que gêneros discursivos diversos, ao adentrar a seara da escola, revestem-se de objetivos didáticos peculiares que demandam dos sujeitos uma leitura específica, a que visa à aprendizagem, à interpretação e que, por isso, beneficia-se do uso de estratégias metacognitivas que são capazes de monitorar a compreensão e de regular a aprendizagem. Ler numa perspectiva metacognitiva envolve a ativação de certo estado perceptivo hipoteticamente desativado em leituras corriqueiras, em que o compromisso daquele que lê é unicamente com seus interesses e intenções momentâneas. Logo, ensinar, na escola, estratégias metacognitivas de leitura, como defendem autores como Ribeiro, Cavalcante e Nunes (2020), é um fazer que beneficia não apenas a disciplina Língua Portuguesa, mas a instituição escola, uma vez que a qualidade da leitura tende a reverberar no desempenho escolar como um todo.

Nessa perspectiva, parece ser possível afirmar que a qualidade da leitura se torna prérequisito para o bom desempenho escolar. Mas seria possível supor que estudantes de alto desempenho apresentam um repertório de estratégias de leitura mais amplo e diversificado que estudantes com baixo desempenho escolar? Em outros termos, a qualidade da leitura estaria intimamente relacionada ao desempenho do estudante ou, ao contrário, estudantes de baixo desempenho escolar também apresentariam um repertório considerável de estratégias de leitura, o que desvincularia a competência leitora do desempenho escolar? Consideramos que o desempenho escolar seja determinado por fatores múltiplos, incluindo aspectos de ordem material e emocional. Assim, embora a competência leitora não seja a única instância a definir o bom desempenho escolar, parece-nos que tampouco ele se estabelece sem ela. Esclarecer a natureza das relações entre o uso de estratégias de leitura e o desempenho escolar traz o benefício de se compreender até que ponto processos de ensino podem se beneficiar da perspectiva metacognitiva.

A partir dessas questões, este estudo objetiva delinear, sob uma perspectiva sociocognitiva, quais são as relações observáveis entre mobilização de estratégias metacognitivas de leitura e o desempenho escolar. Para tanto, aplicamos uma escala de estratégias de leitura, constante de estratégias globais, estratégias de suporte à leitura e estratégias de solução de problemas, a dois grupos de estudantes do Ensino Médio (EM): um com alto desempenho em português e matemática, outro com baixo desempenho nessas disciplinas. A partir dos resultados, focalizamos os tipos de estratégias utilizadas em cada grupo, assim como a porcentagem de uso, possibilitando reflexões mais fundamentadas sobre as relações entre desempenho escolar e uso de estratégias de leitura, com o objetivo de fazer o ensino de leitura numa perspectiva metacognitiva chegar à escola, como argumentam Cavalcante e Ribeiro (2016).

A seguir, apresentamos o conceito de leitura que serve a esta pesquisa, assim como a base psicolinguística que fundamenta a discussão sobre estratégias metacognitivas de leitura. Em seguida, apresentamos os procedimentos metodológicos da pesquisa e, na sequência, os resultados das análises dos dados, conduzindo o leitor para as considerações finais deste estudo.

\section{LINHA D'́GUA}




\section{Leitura como atividade sociocognitiva}

Para discutir as relações entre desempenho escolar e leitura, ou mais precisamente, entre desempenho escolar e estratégias metacognitivas de leitura, é preciso definir de que leitura se fala, apontando para a relevância social dessa habilidade, em primeiro lugar, e para os fundamentos (meta)cognitivos dela, na sequência.

Embora o foco deste estudo esteja na leitura que visa à aprendizagem, não entendemos a leitura apenas em seu aspecto técnico e psicolinguístico. Ao contrário, é por compreendê-la a partir de uma abordagem ampla e social como a de Freire (1989) que vislumbramos a relevância de se abordar o seu aspecto técnico.

Para ler e compreender, é preciso partir do mundo, mas também chegar a ele para inferir, para propor hipóteses e para se lançar à aventura de produzir sentidos. Como definiu Freire (1989, p. 9), "a leitura do mundo precede a leitura da palavra, daí que a posterior leitura dela não pode prescindir da continuidade daquele". Nessa perspectiva, a leitura não se processa entre o sujeito e a materialidade linguística do texto, mas entre o sujeito, o texto e o mundo, que pode ser representado pelo conhecimento prévio que o sujeito aporta para compreender, interpretar e produzir sentidos.

A leitura se mostra, desse modo, como um diálogo interno do sujeito com seus conhecimentos e do sujeito com o mundo. Nesse movimento entre o mundo representado/partilhado e seus sistemas de conhecimento, o sujeito leitor se coloca perante o mundo como um sujeito do saber. Como habilidade cognitiva fundamental à inserção em práticas sociais letradas, a leitura proporciona ao indivíduo não apenas a oportunidade de usufruir do legado cultural escrito de sua época, mas também a de contribuir com ele, seja produzindo, seja opinando e participando como cidadão de direito. Saber ler e ler bem colocase, dessa maneira, como um direito social fundamental aos nossos dias. Logo, proporcionar a todos possibilidades de agir e interagir por meio da leitura e da escrita é um fazer que está na base de uma sociedade menos desigual, do ponto de vista social e educacional.

Silva (1993, p. 43) nos lembra que a crise de leitura não é um problema de nossos dias. Ela advém do período colonial, quando a "participação desigual das classes sociais no que tange ao acesso à fruição dos conhecimentos veiculados pela escrita e das formas arbitrárias e fetichizadas de se conceber e se produzir a leitura" excluíam a maior parte da população da escola. Hoje, apesar da universalização da educação, grande parte da população continua alijada do sistema de poder centralizado na escrita. Como explica o autor, a leitura, assim como outras práticas de cunho social e comunicacional, sempre esteve submetida "[...] à política de reprodução do sistema de privilégios, onipresente e enraizada na estrutura social brasileira ao longo dos tempos" (SILVA, 1993, p. 44). Dessa forma, ler bem, com segurança e autonomia, no Brasil, ainda não é uma conquista para todos - o que nos move na direção de reflexões que pensam na democratização da leitura.

\section{LINHA DÁGUA}


Uma das formas de frear a reprodução de sistemas de privilégios em nosso país é oferecer uma educação democrática e crítica que eduque para além da cultura do silêncio, numa perspectiva emancipatória, possibilitando autonomia intelectual e reflexiva por meio da leitura (OLIVEIRA; SANTOS; PRIMI, 2003; FERRAREZI JR., 2018). Acreditamos que a autonomia em leitura pode reverberar de maneira significativa em diversas instâncias da vida social, uma vez que a competência leitora é um diferencial que envolve apropriação de conhecimento e, por consequência, (re)distribuição de poder. Assim, não seria exagero dizer que a autonomia em leitura pode se estender a outros tipos de autonomia, como a educacional, a intelectual e até mesmo a vivencial, que pode se traduzir num alargamento de fronteiras diversas.

Nesse sentido, entender o ato de ler como um exercício que envolve contextos, sujeitos, conhecimentos, interações, saberes, fazeres, memórias e experiências é fundamental para que se possa compreender o papel da leitura em nossas vidas. Dificuldades em leitura, por essa ótica, além de estreitarem o universo de conhecimento do sujeito, diminuem também as possibilidades de vivência, ratificando a impressão de que os prejuízos estão para além das perdas escolares.

Logo, dificuldades em leitura ocasionam ao sujeito limitações na escola, mas também nos espaços de atuação social. Como afirma Mello (2016, p. 3), "é inquestionável a importância da leitura para a inserção social dos indivíduos nos mais variados contextos pelos quais circulam", visto que a atividade não se desenvolve apenas num sentido informativo, mas também formativo, propiciando "o desenvolvimento de várias habilidades como a criatividade e o espírito crítico dos indivíduos". Zacarias e Palma (2013, p. 6) esclarecem que, quando a aprendizagem traz significados relevantes ao aprendiz, "ela ocorre de maneira concreta, possibilitando ao indivíduo atuar como cidadão consciente de seus direitos e deveres no meio em que vive".

\section{Estratégias de leitura e metacognição}

Demonstrada a inegável importância da leitura para a vida social e escolar, perguntamos o que se pode fazer para levar os sujeitos a lerem melhor. Entre diversas possibilidades, apontamos, neste estudo, para a perspectiva metacognitiva, que pode ser traduzida pelo despertar da consciência do sujeito sobre o seu próprio processamento leitor: "como eu leio? Quais são as minhas dificuldades de leitura? O que influencia na velocidade ou lentidão do meu processamento leitor? O que faço para ter acesso a informações implícitas?" Cavalcante e Ribeiro (2016, p. 4) sustentam que essas "são algumas das questões que costumam guiar o entendimento do próprio processamento leitor numa perspectiva de ensino de leitura por meio do desenvolvimento da metacognição". Leitores experientes fazem esse tipo de questionamento de maneira inconsciente e corrente. Já leitores iniciantes podem ser guiados pelo professor, para criarem estratégias capazes de mitigar problemas de compreensão.

\section{LINHA D'́GUA}


Estudadas por muitos pesquisadores das áreas de leitura e aprendizagem, as estratégias de leitura apresentam-se como um recurso bastante efetivo na promoção de uma leitura eficaz. Mello (2016, p. 6) explica: “[...] denominam-se estratégias os métodos utilizados para alcançar o objetivo proposto, no caso em estudo, a compreensão textual”. Joly, Santos e Marini (2006, p. 205) definem que "as estratégias de leitura são habilidades usadas para promover a compreensão em situações de leitura”. Seja método, seja habilidade, a estratégia de leitura é uma ação que visa suportar a realização de um dado objetivo prévio, de modo a otimizar o processo de leitura, melhorando o desempenho, por meio de ações de monitoria e de regulação da própria compreensão e aprendizagem. É sabido que estratégias de leitura podem ser desenvolvidas naturalmente por leitores experientes, mas ensiná-las acelera o processo, promovendo o desenvolvimento da habilidade em leitura. Vale ressaltar que as estratégias podem e, por vezes, devem se adequar à situação leitora, ou seja, as estratégias se adaptam conforme o gênero de texto, os objetivos da leitura, a abordagem a ser considerada, entre outras variáveis.

Considerando, então, a existência de estratégias de leitura, trazemos à tona, aqui, dois grupos de atividades mentais que se diferenciam quanto ao procedimento envolvido nos processos estratégicos: estratégias cognitivas e estratégias metacognitivas. As estratégias cognitivas de leitura caracterizam-se por contribuírem, influenciando o processo de leitura, com a "decodificação de símbolos linguísticos", com a "construção de significado e com o armazenamento mais eficiente de informações na cognição", como expõem Joly, Santos e Marini (2006, p. 205). Referindo-se ao processo cognitivo envolvido na leitura, Neves (2007, p. 2) explica que "a cognição humana apresenta-se como uma reprodução dos conhecimentos estocados na memória, acompanhados das interpretações que lhe são associadas e das formas de processamento de informações, como, por exemplo, o processamento textual". Processos cognitivos, a rigor, não estão necessariamente sob monitoria e controle; quando passamos a regulá-los, entramos na seara da metacognição.

A atividade metacognitiva demanda uma percepção ativa do próprio sistema cognitivo. Para Schraw (1998), enquanto a cognição mobiliza habilidades necessárias à realização de uma tarefa, a metacognição se empenha para compreender e para avaliar o andamento da realização dessa tarefa, corrigindo rotas, se necessário. Logo, o sistema metacognitivo ocorre em concomitância ao sistema cognitivo, monitorando-o e regulando-o. Aplicando esse entendimento ao ato de ler, Marini e Joly (2008) definem estratégias metacognitivas de leitura como ações decorrentes do estado de percepção consciente que o leitor desenvolve/ativa sobre o próprio nível de compreensão da leitura, incluindo a habilidade para gerenciar ações cognitivas por meio de atos capazes de facilitar o entendimento de um determinado texto ou tarefa. Por meio do uso de estratégias, o leitor consegue planejar, monitorar e regular a sua própria cognição no curso da leitura (JOLY; SANTOS; MARINI, 2006). Por serem metacognitivas, as estratégias refletem no próprio processo cognitivo envolvido no ato da leitura, isto é, organizam o pensamento na atividade leitora, de modo a identificarem dificuldades encontradas na leitura; a relacionarem as informações assimiladas com outras

\section{LINHA DÁGUA}


informações de conhecimento prévio; a administrarem determinadas situações envolvidas; a traçarem objetivos para a leitura do texto; e a controlarem o processo leitor de maneira geral, mantendo a consciência e o domínio sobre ele.

Quando pensamos na atividade metacognitiva relacionada à leitura e à aprendizagem, estamos pensando também na capacidade de planejamento (por onde vou começar? O que preciso destacar?), de monitoramento da compreensão (quando parei de compreender? Por que a minha leitura ficou mais lenta nesse trecho?) e da regulação da aprendizagem (preciso retomar dado trecho e listar dados aspectos do que li para fixar a aprendizagem). Boruchovitch (1999) esclarece que isso significa uma tomada de consciência da apropriação e da produção de conhecimento, o que implica o aprender a aprender, em função de uma aprendizagem de fato mais consciente e eficaz, visto que, dessa forma, o aprendiz passa a possuir algum domínio e conhecimento sobre os seus próprios processos mentais.

Schraw (1998) pontua que a metacognição se dá em dois planos: no conhecimento da cognição e na regulação da cognição. $O$ conhecimento da cognição acontece a partir das consciências declarativa (formular o conhecimento sobre si), procedimental (ter conhecimento de como fazer as atividades) e condicional (ter conhecimento do porquê e do quando dos aspectos referentes à cognição), ou seja, envolve conhecer a própria cognição. A regulação da cognição, partindo do conhecimento da cognição, efetiva-se nas habilidades de planejamento (seleção de estratégias adequadas e preparação para o desempenho da atividade), de monitoramento (que acompanha o desempenho da atividade) e de avaliação (que afere a eficiência da atividade desempenhada).

O conhecimento da cognição e a regulação da cognição estão relacionados entre si em função da aprendizagem exitosa por meio do desenvolvimento de habilidades. Segundo Schraw (1998, p. 123, tradução nossa), "a metacognição é essencial para o sucesso da aprendizagem, porque permite que os indivíduos gerenciem melhor as suas fraquezas, que podem ser corrigidas pela construção de novas habilidades metacognitivas". Conforme apontado pelo autor, o exercício da metacognição implica um perfil universal, isto é, é aplicável às mais variadas áreas de conhecimento e atividades, contribuindo com a boa performance do aprendiz.

Dessa forma, a gestão consciente dos processos cognitivos é de fundamental relevância também quando trabalhada na atividade leitora. Mello (2016) explica que as estratégias de aprendizagem mais eficientes são descobertas a partir do exercício metacognitivo do próprio leitor. Assim, o domínio da leitura compreende uma série de habilidades relacionadas à competência leitora, através da relação de informações textuais com informações extratextuais do uso de estratégias de leitura, do elo entre os conhecimentos prévios e os trazidos pelo texto, de conexões entre o texto e o mundo, entre outras.

Alunos que são bons leitores tendem a desempenhar um rendimento melhor em atividades cognitivas (embora a literatura não correlacione isso, exclusivamente, ao uso de estratégias metacognitivas de leitura). Eles conseguem identificar e filtrar, na leitura,

\section{LINHA DÁGUA}


informações importantes para a compreensão do conteúdo, revelando domínio do processo de leitura, que é, evidentemente, um processo de aprendizagem. Essa tomada de consciência dos processos da aprendizagem atribui ao aprendiz a autonomia já mencionada, uma vez que ele conhece a si mesmo, como recomendado pelo filósofo grego Sócrates.

Joly, Santos e Marini (2006, p. 206) explicam que "leitores hábeis fazem, freqüentemente [sic], uma análise geral do texto e frente a dificuldades de compreensão das informações usam estratégias que possam auxiliar o entendimento da informação", o que revela a autonomia existente no processo de aprendizagem do sujeito que lê com proficiência. Sobre a emancipação autônoma do leitor, Boruchovitch (2001, p. 24) expõe a necessidade de profissionais envolvidos na educação, sobretudo, professores de Língua Portuguesa, desenvolverem trabalhos preventivos dedicados à "formação do leitor independente, crítico e reflexivo".

A autonomia observada nesses alunos que realizam atividades metacognitivas na leitura, denominados, por Boruchovitch (2001), como "bons leitores", não se faz presente na aprendizagem dos chamados "maus leitores", visto que estes não tendem a desempenhar exercícios metacognitivos no ato da leitura. Isso sugere o quanto "o domínio da leitura é essencial para se obter sucesso na escola, sendo necessário na maior parte das situações acadêmicas" (BORUCHOVITCH, 2001, p. 20). Na presente pesquisa, olharemos para o uso que grupos de estudantes com alto e baixo desempenho escolar fazem das estratégias de leitura, a fim de refletir sobre as relações entre desempenho escolar e estratégias de leitura.

Joly, Santos e Marini (2006) defendem a necessidade de se discutir, a partir do âmbito escolar, a importância da metacognição na construção da habilidade leitora, na formação de leitores. Concordando com essa percepção, ressaltamos que importa que os alunos, além de aprenderem as estratégias, saibam como e quando utilizá-las. Nem toda estratégia metacognitiva de leitura serve para todos os textos, assim como não serve para todos os leitores. Por esse motivo, é necessário que se oportunize a tomada de consciência dos alunos dos seus próprios processos de aprendizagem e de leitura, pois, uma vez conscientes de si, os alunos adaptam, desenvolvem e utilizam estratégias conforme as necessidades da realidade do texto com o qual se deparam: os alunos emancipam-se, criam autonomia de leitura e, por consequência, melhoram a competência leitora (BORUCHOVITCH, 2001). Como explicam Ribeiro, Cavalcante e Nunes (2020, p. 16), “ensinar a pensar e a tomar atitudes em busca da compreensão [...] tende a transformar os alunos em leitores mais ativos e engajados em seu próprio processo de compreensão".

De nosso ponto de vista, o ensino de estratégias metacognitivas faz-se de significativa importância nas aulas de Língua Portuguesa. Como Boruchovitch (2001) aponta, muitas vezes, espera-se do aluno habilidades que não são ensinadas e oportunizadas, uma vez que as

2 Boruchovitch (2001) refere-se aos leitores proficientes como "bons leitores" e aos não proficientes como "maus leitores", embora essas expressões não nos pareçam adequadas.

\section{LINHA DÁGUA}


habilidades de leitura se viabilizam, em grande parte, por meio do uso de estratégias metacognitivas de leitura, ainda que o aluno não se dê conta disso. Logo, esse ensino é de fundamental relevância para que os alunos desenvolvam habilidades metacognitivas, que são amadurecidas dentro dos processos mentais e práticos leitores com o tempo de uso, mas que podem ser acelerados pelo ensino direto (NEVES, 2007).

Joly (2006), fazendo menção aos estudos de Pearson e Camperell (2001), divide as estratégias metacognitivas de leitura em três grupos, procedimento utilizado neste trabalho em relação à escala de estratégias que será utilizada na coleta de dados. Nessa perspectiva, as estratégias podem ser consideradas globais, estratégias de suporte à leitura ou estratégias de solução de problemas. As estratégias globais são úteis à compreensão leitora num sentido amplo (como lançar uma hipótese de compreensão a ser confirmada, por exemplo), enquanto as estratégias de suporte à leitura envolvem o uso de anotações, materiais de referência e consultas diversas. As estratégias de solução de problemas são utilizadas em situações em que o leitor encontra um problema de compreensão textual e mobiliza esforço para saná-las.

As estratégias podem se diferenciar ainda pelo momento em que ocorrem, como discute Solé (1998). Há estratégias que são empreendidas antes da leitura (como ver a organização do texto e determinar metas); outras ocorrem durante o ato de ler (como fazer consultas a outras fontes ou fazer destaques no texto); outras, ainda, só ganham corpo quando a leitura se encerra (como fazer um resumo ou uma lista de dúvidas).

Assim, reafirmamos que o processo de metacognição se dá no exercício da leitura, a partir de estratégias, isto é, por meio de procedimentos aos quais se recorrem para que seja possível alcançar os objetivos almejados. O exercício da metacognição por meio dessas variadas estratégias de leitura permite que o processo de leitura não seja apenas uma decodificação, mas um exercício de integração com o texto e, por consequência, com o meio social através da compreensão leitora.

Por fim, considerando que práticas leitoras podem possibilitar, sob uma ótica sociocultural, inserção social e autonomia intelectual, entendemos que a metacognição na leitura, de forma indireta, contribui para esses processos, por diminuir a experiência da incompreensão, o que leva o sujeito a esquivar-se de textos escritos. Se o uso de estratégias metacognitivas de leitura contribui com a proficiência leitora, em que medida podemos relacionar o uso de estratégias ao desempenho escolar? Estudantes com alto desempenho escolar lançariam mão de estratégias de leitura em maior proporção que estudantes com baixo desempenho? Discutiremos esses aspectos nas seções a seguir.

\section{Procedimentos metodológicos}

Nesta pesquisa de abordagem mista (qualitativa/quantitativa), visando aos objetivos descritivos, intencionamos entender se estudantes de alto e baixo desempenho escolar se

\section{LINHA DÁGUA}


diferem do ponto de vista do uso de estratégias metacognitivas de leitura. A hipótese do estudo parte do entendimento de que estudantes de alto desempenho apresentam um repertório de estratégias de leitura mais vasto que estudantes de baixo desempenho, o que poderia justificar, pelo menos parcialmente, a diferença de desempenho entre os grupos.

Para investigar as relações entre desempenho escolar e estratégias metacognitivas de leitura, a pesquisa selecionou alunos do $2^{\circ}$ ano do EM para compor dois grupos-controle: um constituído por estudantes de alto desempenho, outro constituído por estudantes de baixo desempenho escolar ${ }^{3}$. Em seguida, em reunião com os sujeitos da pesquisa, uma escala de estratégias metacognitivas de leitura lhes foi aplicada, a fim de que revelassem quais são as estratégias que cada grupo utiliza. Cada participante recebeu uma folha de papel com a escala de estratégias, na qual deveria indicar, circulando no papel, as estratégias que costuma utilizar em leituras escolares. A escala foi elaborada por Joly, Santos e Marini (2006) e conta com 39 estratégias, sendo 13 estratégias metacognitivas globais, 10 estratégias metacognitivas de suporte à leitura e 15 estratégias de solução de problemas (vide apêndice).

A escolha por alunos do $2^{\circ}$ ano justifica-se pelo fato de que, geralmente, os alunos do $1^{\circ}$ ano ainda estão em uma fase de adaptação ao Ensino Médio, considerando a trajetória percorrida no Ensino Fundamental; e pelo fato de os alunos do $3^{\circ}$ ano estarem, a rigor, envolvidos com a preparação para o ENEM, o que poderia gerar indisponibilidade para a pesquisa. Essas razões posicionaram o $2^{\circ}$ do Ensino Médio como ideal para a investigação.

Para a seleção dos sujeitos, dispusemo-nos da indicação dos professores ${ }^{4}$ que lecionavam as disciplinas de Língua Portuguesa e de Matemática nas turmas do $2^{\circ}$ ano disciplinas cuja aprendizagem é aferida em avaliações em larga escala. Assim, solicitamos que indicassem nomes de alunos frequentes que apresentavam alto desempenho ${ }^{5}$ na disciplina que lecionavam, assim como de alunos frequentes que apresentavam baixo desempenho ${ }^{6}$, de modo que fosse considerada, para a seleção dos alunos, não apenas a média escolar, mas a percepção do professor em relação a sua aprendizagem, o que também difere de participação e interatividade. Ao comparar as listas, selecionamos os nomes que estavam na mesma categoria (alto desempenho ou baixo desempenho) tanto em português quanto em matemática. Eliminados os sujeitos que estavam na lista de uma única disciplina e aqueles que não manifestaram interesse pela pesquisa, chegamos a uma lista com 8 sujeitos: quatro estudantes considerados de alto desempenho em português e matemática e quatro estudantes de baixo desempenho nessas disciplinas.

3 Este estudo seguiu todos os procedimentos de ética em pesquisa recomendados pela Comissão Nacional de Ética em Pesquisa (CONEP), tendo sido aprovado por esse órgão. Entre os procedimentos, destacamos a apresentação de termo de assentimento, preservação da identidade dos participantes e explicitação de riscos e garantias, entre outros.

4 Reconhecemos o caráter subjetivo da classificação do desempenho dos estudantes, uma vez que não ele se baseia em instrumentos com padronização passível de excluir algum nível de subjetividade.

5 Os professores foram instruídos de que os alunos de alto desempenho a serem indicados não seriam aqueles com boa participação e engajamento, mas aqueles que apresentam resultados de aprendizagem elevados.

6 Os alunos de baixo desempenho a serem indicados não poderiam apresentar laudos ou suspeitas de deficiência. Não poderiam, também, ser pouco frequentes ou pouco comprometidos (do tipo que não realiza as atividades).

\section{LINHA DÁGUA}


Selecionados os sujeitos, uma escala de estratégias metacognitivas de leitura lhes foi aplicada, para que indicassem quais estratégias utilizavam durante as leituras. $\mathrm{Na}$ escala apresentada, acrescentamos, ao final, um espaço para que os participantes informassem se utilizavam estratégias não previstas no instrumento (vide apêndice). A partir dos estudos de Pearson e Camperell (2001), as estratégias de leitura da escala foram divididas em três grupos: estratégias metacognitivas globais; estratégias metacognitivas de suporte à leitura e estratégias metacognitivas de solução de problemas. Essa divisão não foi informada aos participantes da pesquisa, mas se mostrou relevante para a análise dos dados. As estratégias adicionadas pelos próprios participantes também foram, posteriormente, classificadas nesses grupos.

Selecionados os alunos, foi marcado, ao final do ano letivo, um encontro, para que os participantes da pesquisa e os pesquisadores pudessem se conhecer, de modo a serem esclarecidos, em panorama geral, os objetivos do estudo e a importância da pesquisa para a educação ${ }^{7}$. Em encontro posterior, agendado de acordo com a disponibilidade dos participantes e dos pesquisadores, o instrumento de coleta de dados foi aplicado aos participantes da pesquisa. Nessa ocasião, outros instrumentos de coleta de dados, como um teste de leitura assistido, foram realizados. Neste estudo, todavia, estringimos a discussão ao uso de estratégia de leituras.

\section{Resultados e discussão}

Nesta seção, apresentamos a análise dos dados por meio de interpretações qualitativas dos resultados quantitativos. As tabelas demonstram, por grupo, o uso de estratégias de leitura apontadas como usuais pelos estudantes. Assim, considerando o total de estratégias por subtipos, apresentamos a porcentagem de uso por cada estudante e por cada grupo de estudantes, incluindo, na discussão, as estratégias acrescentadas à escala pelos próprios estudantes. A intenção, por meio desse procedimento, é construir um perfil de uso de estratégias por grupo, e para isso, partimos das seguintes categorias: a) predominância de estratégias, a partir de subtipos, em cada aluno; b) predominância de tipos de estratégia em cada grupo de estudantes; c) estratégias acrescentadas por estudantes/grupos de estudantes.

Em relação à primeira categoria, consideradas as estratégias destacadas pelos alunos como recursos de que se utilizam em seus processos de leitura, identificamos, por aluno, a porcentagem aproximada de uso de estratégias relativas a cada subtipo. No total de 39 estratégias constantes na escala, como dito, 13 eram estratégias globais, 11 de suporte à leitura e 15 de solução de problemas, segundo a classificação de Pearson e Camperell (2001). Alice, Tereza, Antônio e Ester são os participantes que compõem o grupo de alunos de alto desempenho escolar, enquanto Francisco, Jorge, Olga e Dulce compõem o grupo de alunos de baixo desempenho escolar ${ }^{8}$.

7 Este estudo compõe um estudo maior intitulado "Leitura e metacognição: diferenças estratégicas entre estudantes com alto e baixo rendimento escolar". O recorte que apresentamos aqui focaliza um dos instrumentos da pesquisa, que contou com outros instrumentos, incluindo entrevistas e testes de leitura

8 Nomes fictícios que preservam a identidade dos participantes da pesquisa.

\section{LINHA DÁGUA}


Tabela 1. Percentual de estratégias utilizadas por aluno

\begin{tabular}{c|c|c|c|c|c}
\hline $\begin{array}{c}\text { Grupo } \\
\text { controle }\end{array}$ & Estudante & $\begin{array}{c}\text { Estratégias } \\
\text { globais }\end{array}$ & $\begin{array}{c}\text { Estratégias } \\
\text { de suporte à } \\
\text { leitura }\end{array}$ & $\begin{array}{c}\text { Estrat. de } \\
\text { solução de } \\
\text { problemas }\end{array}$ & $\begin{array}{c}\text { Total de } \\
\text { estratégias } \\
\text { utilizadas }\end{array}$ \\
\hline \multirow{2}{*}{$\begin{array}{c}\text { Alto } \\
\text { desempenho }\end{array}$} & Alice & $69 \%$ & $73 \%$ & $87 \%$ & $77 \%$ \\
\cline { 2 - 6 } escolar & Tereza & $54 \%$ & $55 \%$ & $67 \%$ & $59 \%$ \\
\cline { 2 - 6 } & Antônio & $46 \%$ & $64 \%$ & $73 \%$ & $62 \%$ \\
\hline \multirow{2}{*}{$\begin{array}{c}\text { Baixo } \\
\text { desempenho }\end{array}$} & Ester & $38 \%$ & $27 \%$ & $67 \%$ & $46 \%$ \\
\hline Escolar & Joncisco & $54 \%$ & $18 \%$ & $93 \%$ & $59 \%$ \\
\cline { 2 - 6 } & Olga & $23 \%$ & $27 \%$ & $73 \%$ & $44 \%$ \\
\hline \multirow{2}{*}{ Orge } & $15 \%$ & $0 \%$ & $27 \%$ & $15 \%$ \\
\hline
\end{tabular}

Fonte: Elaborado pelos autores

Observa-se, na tabela $1^{9}$, que o tipo de estratégia mais utilizada pelos dois grupos é a de solução de problemas. Na escala, havia mais estratégias desse tipo, o que, somado às necessidades constantes de se repararem problemas de compreensão, justifica o fato de as estratégias de solução de problemas possuírem um maior percentual de incidência. Para além da quantidade maior de estratégias de solução de problemas constante na escala, isso revela que os alunos, tanto de baixo quanto de alto desempenho, tendem a recorrer às estratégias, principalmente, quando se deparam com algum problema para entender o texto, uma vez que, como afirmam Joly; Santos e Marini (2006, p. 2006), "as [estratégias] de solução de problemas são usadas quando surgem dificuldades de compreensão para o leitor frente às informações apresentadas no texto". Nota-se, inclusive, que o grupo de baixo desempenho utiliza-se mais dessa estratégia que o grupo de alto desempenho.

Quando se considera o percentual de estratégias destacadas por aluno, percebe-se que os alunos Ester (alto desempenho) e Francisco (baixo desempenho) apresentam comportamentos que diferem dos demais integrantes dos seus respectivos grupos. O percentual total aproximado de estratégias marcadas por Ester é de $46 \%$, ao passo que o percentual referente às estratégias utilizadas por Francisco é de 58\%. Podemos entender esse fenômeno como uma exceção, uma vez que a maioria dos integrantes do grupo de alto desempenho indicou utilizar mais de 50\% das estratégias constantes na escala, e a maioria dos integrantes do grupo de baixo desempenho indicou utilizar menos de 50\% das estratégias. Outra possibilidade de compreensão seria considerar o desempenho escolar como um contínuo que parte do mais baixo estrato e chega ao mais alto estrato. No meio desse contínuo, haveria uma zona limítrofe entre o baixo desempenho e o alto desempenho. Assim, enquanto Francisco se

9 Os números percentuais presentes neste artigo foram arredondados: para menos, quando os décimos eram menores que 0,5 ; e para mais, quando os décimos eram maiores que 0,5 .

\section{LINHA DÁGUA}


posicionaria no nível mais alto do grupo "baixo desempenho", Ester se posicionaria no nível mais baixo do grupo de "alto desempenho", fazendo com que estes extremos (o mais elevado de um grupo e o mais baixo de outro) se aproximem.

A Tabela 2 refere-se ao percentual médio de cada grupo em relação aos tipos de estratégias utilizadas e ao percentual geral dos grupos, considerando todas as estratégias:

Tabela 2. Percentual médio de estratégias utilizadas pelos grupos

\begin{tabular}{c|c|c|c|c}
\hline Grupo controle & Globais & Suporte à leitura & $\begin{array}{c}\text { Solução de } \\
\text { problemas }\end{array}$ & $\begin{array}{c}\text { Média total do } \\
\text { grupo }\end{array}$ \\
\hline $\begin{array}{c}\text { Alto desempenho } \\
\text { escolar }\end{array}$ & $52 \%$ & $55 \%$ & $73 \%$ & $61 \%$ \\
\hline $\begin{array}{c}\text { Baixo desempenho } \\
\text { escolar }\end{array}$ & $27 \%$ & $14 \%$ & $55 \%$ & $34 \%$ \\
\hline
\end{tabular}

Fonte: Elaborado pelos autores

Em relação à segunda categoria, ao se considerarem os percentuais médios, o fenômeno de maior recorrência de estratégias de solução de problemas é novamente observado, o que confirma a constatação já pontuada. Considerando a média total dos grupos, nota-se que o grupo controle de alunos de alto desempenho escolar utiliza um percentual de $61 \%$ das estratégias apresentadas, isto é, mais que a metade das estratégias constantes na escala, enquanto o grupo de alunos de baixo desempenho utiliza aproximadamente $34 \%$ das estratégias constantes na escala. Isso confirma a ocorrência de relações entre o uso de estratégias metacognitivas de leitura, que conforme pesquisas (BORUCHOVITCH, 1999; BORUCHOVITCH, 2001; JOLY, SANTOS, MARINI, 2006; MELLO, 2016; NEVES, 2007), contribui com a competência leitora e, pelo que tudo indica, também para o desempenho escolar.

Ao fim da escala, perguntamos aos sujeitos se eles utilizavam alguma estratégia não apresentada na lista e, em caso positivo, eles deveriam acrescentar (registrar) a estratégia utilizada. Sendo considerados os dois grupos controle supramencionados e as estratégias acrescentadas pelos alunos na escala, obtiveram-se os seguintes resultados: apenas um dos quatro alunos de baixo desempenho escolar acrescentou estratégia de leitura não constante na escala, enquanto os quatro alunos de alto desempenho escolar acrescentaram estratégias não constantes na escala aplicada, como descreve o quadro 1. 
Quadro 1. Estratégias de leitura adicionadas pelos estudantes

\begin{tabular}{|c|c|c|c|}
\hline $\begin{array}{l}\text { Grupo } \\
\text { controle }\end{array}$ & Alunos & $\begin{array}{l}\text { Classificação das } \\
\text { estratégias }\end{array}$ & Estratégias de leitura \\
\hline \multirow{4}{*}{$\begin{array}{c}\text { Alto } \\
\text { desempenho } \\
\text { escolar }\end{array}$} & Alice & Estratégia global & Criar questões sobre o texto e respondê-las \\
\hline & Tereza & $\begin{array}{l}\text { Estratégia de solução de } \\
\text { problemas }\end{array}$ & Procurar o professor para sanar dúvidas \\
\hline & Antônio & $\begin{array}{l}\text { Estratégia de solução de } \\
\text { problemas }\end{array}$ & Repetição oral das informações do texto \\
\hline & Ester & $\begin{array}{l}\text { Estratégia de suporte à } \\
\text { leitura }\end{array}$ & $\begin{array}{l}\text { Procurar outras fontes de informação sobre } \\
\text { o conteúdo do texto }\end{array}$ \\
\hline \multirow{4}{*}{$\begin{array}{c}\text { Baixo } \\
\text { desempenho } \\
\text { escolar }\end{array}$} & Francisco & - & - \\
\hline & Jorge & $\begin{array}{l}\text { Estratégia de solução de } \\
\text { problemas }\end{array}$ & $\begin{array}{l}\text { Adiar em alguns casos para ler com calma } \\
\text { depois }\end{array}$ \\
\hline & Olga & - & - \\
\hline & Dulce & - & - \\
\hline
\end{tabular}

Fonte: Elaborado pelos autores

A terceira categoria demonstra que, como se observa no Quadro 1, apenas um aluno do grupo de baixo desempenho escolar (Jorge) acrescentou nova estratégia de leitura, e os outros três alunos (Francisco, Olga e Dulce) não o fizeram. Noutro giro, os quatro alunos do grupo de alto desempenho (Alice, Tereza, Antônio e Ester) adicionaram novas estratégias. A partir disso e das constatações feitas a partir da média total dos grupos controle, na Tabela 2, podemos refletir sobre como as estratégias de leitura contribuem com o desempenho escolar.

Considerando que as estratégias de leitura existem em função do estabelecimento de uma compreensão leitora, de fato, mais efetiva, reconhecemos o papel que elas desenvolvem na formação do leitor competente e a função de uma leitura competente no desempenho escolar dos estudantes, uma vez que a leitura é fundamental à apropriação de conhecimento formal.

Este estudo corrobora a hipótese de que estudantes com alto desempenho escolar apresentam um repertório de estratégias de leitura mais robusto que o repertório de estratégias de estudantes de baixo desempenho. Esse dado reafirma a importância de se desenvolver e alicerçar as habilidades de leitura escolar por meio do ensino de estratégias de leitura, uma vez que, como dissemos no início deste estudo, embora a qualidade da leitura e a mobilização da metacognição não sejam os únicos fatores envolvido no desempenho escolar, certamente, eles são condição sine qua non.

Considerando que os alunos de baixo desempenho, em sua maioria, não listaram estratégias de leitura não constantes na escala aplicada, diferentemente dos alunos de alto desempenho, podemos atribuir essa ausência, entre outros possíveis motivos, à baixa atividade metacognitiva associada à leitura, e por extensão e consequência, à deficiência leitora e ao baixo desempenho escolar, o que compõe um cenário cíclico.

\section{LINHA DÁGUA}




\section{Considerações finais}

Partindo da compreensão de que estratégias de leitura contribuem para a expansão e consolidação da competência leitora, entendemos como primordial o ensino de estratégias de leitura na escola. Como os dados da pesquisa revelam, estudantes de alto desempenho escolar apresentam maior atividade metacognitiva em leitura que estudantes de baixo desempenho, o que provavelmente repercute na aprendizagem de conteúdos escolares.

Assim, é possível afirmar que, neste estudo, as correlações entre o uso de estratégias metacognitivas de leitura e o desempenho escolar se mostram claras a partir do seguinte delineamento: os estudantes de alto desempenho não apenas apresentaram um uso maior e mais diversificado de estratégia, como também demonstraram usar estratégias para além das arroladas. Duas conclusões podem ser derivadas: i) o grupo de alto desempenho apresenta maior conhecimento metacognitivo e maior experiência metacognitiva, o que parece repercutir na regulação dos modos de ler e aprender; ii) conhecimento e experiência metacognitivos aplicados à leitura parecem estar proporcionando níveis de compreensão que permitem, a esse grupo de estudantes, desfrutar do conhecimento sem empecilhos, ao passo que o segundo grupo, ao contrário, pode estar encontrando barreiras no acesso ao conhecimento em modalidade escrita - barreiras que podem impedi-los de progredir academicamente.

Esse exercício metacognitivo, que é construído por meio do autoconhecimento, isto é, da tomada de consciência de si, justamente, por ser uma atividade reflexiva e consciente, proporciona não apena engajamento e compreensão em leitura, mas também em outras atividades cognitivas relacionadas ao saber, o que repercute no desempenho escolar.

Ensinar leitura por meio de práticas tradicionais de localização e de cópia de fragmentos ou da produção de opinião não fundamentada, formando gerações copistas ou extrapoladoras de sentido, deixou marcas profundas em nossa nação. O que se propõe, desse modo, é que a perspectiva metacognitiva se alie a práticas de leitura mais condizentes com o nosso tempo, como a leitura digital e a multimodal, na formação de leitores mais engajados e conscientes dos processos envolvidos no ato de ler.

\section{Financiamento}

Os autores agradecem à Fundação de Apoio à Pesquisa do Estado de Minas Gerais (FAPEMIG) pelo financiamento da pesquisa por meio do Programa de Bolsas de Iniciação Científica BIC/UNI da Universidade Estadual de Montes Claros (Unimontes).

\section{LINHA DÁGUA}




\section{Referências}

BORUCHOVITCH, E. Algumas estratégias de compreensão em leitura de alunos do ensino fundamental. Psicologia Escolar e Educacional, v.5, n.1, p. 19-25, 2001. Disponível em: https://www.scielo.br/j/pee/a/G9WmdV7RKgL9jLTchrgkfkd/abstract/?lang=pt. Acesso: 6 ago. 2020.

BORUCHOVITCH, E. Estratégias de aprendizagem e desempenho escolar: considerações para a prática educacional. Psicologia: Reflexão Crítica, Porto Alegre, v.12, n.2., 1999. Disponível em: $\quad$ http://www.scielo.br/scielo.php?pid=S0102-79721999000200008\&script=sci arttext. Acesso em: 20 mar. 2020.

BRASIL. Pisa revela baixo desempenho escolar em leitura, matemática e ciências no Brasil. 2019. Disponível em: https://bit.ly/3jxHU5I. Acesso em: 2 set. 2020.

CAVAlCANTE, V. M. P.; RIBEIRO, M. C. M. A. Contribuições do ensino de estratégias metacognitivas de leitura no ensino fundamental. Revista Prolíngua, v. 11, n. 1, p. 27-39, 2016. Disponível em: https://periodicos.ufpb.br/index.php/prolingua/article/view/30628/16141. Acesso: 20 set. 2020.

FERRAREZI JÚNIOR, C. Pedagogia do silenciamento: a escola brasileira e o ensino de língua materna. São Paulo: Parábola Editorial, 2018.

FREIRE, P. A importância do ato de ler: em três artigos que se completam. 23. ed. São Paulo: Autores Associados: Cortez, 1989.

JOLY, M. C. R. A.; SANTOS, L. M.; MARINI, J. A. S. Uso de estratégias de leitura por alunos do ensino médio. Paidéia. p. 205-212. 2006. Disponível em: https://www.scielo.br/j/paideia/a/KyKCHQbpDLmTMBCgsFLrD8R/abstract/?lang=pt. Acesso: julho de 2021.

JOLY, M. C. R. A. Escala de estratégias de leitura para etapa inicial do ensino fundamental. Estudos de Psicologia (Campinas), v. 23, p. 271-278, 2006. Disponível em: https://www.scielo.br/j/estpsi/a/rw7t3LwXVGpqxYgqYDBM7Lw/abstract/?lang=pt. Acesso em: 18 ago. de 2021.

MARINI, J. A; JOLY, M. C. R. A. A leitura no Ensino Médio e o uso das estratégias metacognitivas. Estudos e pesquisas em Psicologia, v. 8, n. 2, p. 505-522, 2008. Disponível em: https://www.redalyc.org/pdf/4518/451844626024.pdf. Acesso em: 10 jan. 2021.

MELLO, M. T. Estratégias de compreensão leitora na Universidade. Linguagens \& Cidadania, v. 18, jan./dez. 2016. Disponível em: https://periodicos.ufsm.br/LeC/article/view/28226. Acesso: 6 ago. 2020.

NEVES, D. A. B. Leitura e metacognição: uma experiência em sala de aula. Enc. Bibli: $R$. Eletr. Bibliotecon. Ci. Inf., Florianópolis, n. 24, p. 1-9, $2^{\circ}$ sem.2007. Disponível em: https://periodicos.ufsm.br/LeC/article/view/28226. Acesso em: 23 set. 2020.

OLIVEIRA, K. L.; SANTOS, A. A. A; PRIMI, R. Estudo das relações entre compreensão em leitura e desempenho acadêmico na universidade. Interação em Psicologia. p. 19-25, jan./jun. 2003. Disponível em: https://revistas.ufpr.br/psicologia/article/view/3203. Acesso em: 19 set. 2020 .

PEARSON, P. D.; CAMPERELL, K. Comprehension of text structures. In: RUDDELL, M. R.; SINGER, H. (Orgs.). Theorical Models and Processes of Reading. Newark: Internacional Reading Association, 2001, p. 448-468.

\section{LINHA D'́GUA}


RIBEIRO, M. C. M. A.; CAVAlCANTE, V. M. P.; NUNES, C. T. P. Práticas de ensino de leitura numa perspectiva metacognitiva. Educação em Perspectiva (ONLINE), v. 11, p. 1-18, 2020. Disponível em: https://periodicos.ufv.br/educacaoemperspectiva/article/view/8627. Acesso em: 05 jul. 2021.

SCHRAW, G. Promoting general metacognitive awareness. Instructional Science, 26, p. 113125, 1998. DOI: http://doi.org/10.1023/A:1003044231033. Acesso em: 20 mar. 2021.

SILVA, E. Leitura na escola e na biblioteca. 4. ed. São Paulo: Papirus, 1993.

SOLÉ, I. Estratégias de leitura. Porto alegre: Artes médicas, 1998.

ZACARIAS, I. L.; PALMA, R. C. B. A importância da leitura para o desempenho escolar, o crescimento intelectual e a emancipação do aluno. In: PARANÁ. Os desafios da escola pública paranaense na perspectiva do professor PDE. Curitiba: SEED, 2013. s/n.

\section{Apêndice}

\section{Caro Estudante,}

Esta atividade objetiva coletar dados para o desenvolvimento da pesquisa Leitura $e$ metacognição: diferenças estratégicas entre estudantes com alto e baixo desempenho escolar, desenvolvida por professores e acadêmicos do curso de Letras-Português da Universidade Estadual de Montes Claros. Agradecemos a sua participação e garantimos o seu anonimato, conforme informações disponíveis no Termo de Assentimento assinado por você.

\section{ESCALA DE ESTRATÉGIAS DE LEITURA (adaptada de Joly, Santos e Marini, 2006).}

Caro estudante, a lista abaixo apresenta estratégias que podem ser utilizadas no momento da leitura escolar. Será que você se utiliza de algumas delas quando lê textos da escola? Se sim, circule o número da(s) estratégia(s) que você costuma utilizar. Caso não se utilize de nenhuma delas, deixe a folha em branco.

1. Ver como é a organização do texto.

2. Organizar um roteiro para ler.

3. Levantar hipóteses sobre o conteúdo do texto.

4. Fazer comentários críticos sobre o texto.

5. Opinar sobre as informações do texto.

6. Parar de ler para ver se estou entendendo.

7. Reler trechos quando encontro uma informação que tenho dificuldade de entendimento.

8. Reler em voz alta os trechos que não compreendi.

9. Voltar a ler alguns parágrafos ou páginas já lidas quando me distraio.

10. Verificar se as hipóteses que fiz sobre o conteúdo do texto estão certas ou erradas.

11. Grifar o texto para destacar as informações que acho importante.

12. Fazer anotações ao lado do texto. 
13. Consultar o dicionário para entender o significado de palavras novas.

14. Fixar a atenção em determinados trechos do texto.

15. Fazer anotações sobre os pontos mais importantes do texto.

16. Ler novamente trechos do texto quando não entendo a relação entre as informações.

17. Relacionar o assunto do texto com o que já conheço sobre o assunto.

18. Deduzir informações do texto que leio para compreendê-lo.

19. Analisar se as informações são lógicas e fazem sentido.

20. Ler com atenção e devagar para ter certeza que estou entendo o texto.

21. Reler trechos para relacionar as informações do texto.

22. Questionar o texto para entendê-lo melhor.

23. Concentrar-me na leitura quando o texto é difícil.

24. Ficar atento aos nomes, datas, épocas e locais que aparecerem no texto para compreendê-lo.

25. Fazer suposições sobre o significado de um trecho do texto quando não entendo.

26. Interpretar o que o autor quis dizer.

27. Ler em voz alta quando o texto é difícil.

28. Diferenciar as informações da opinião do autor.

29. Pensar sobre por que fiz algumas suposições certas e outras erradas sobre o texto.

30. Relembrar os principais pontos do texto para verificar se o compreendi totalmente.

31. Escrever com minhas palavras as informações que destaquei como mais importantes.

32. Fazer lista dos tópicos mais importantes do texto.

33. Fazer um resumo do texto para organizar as informações mais importantes.

34. Verificar se atingi o objetivo que havia estabelecido para a leitura.

35. Identificar as dicas do texto que me permitiram fazer hipóteses corretas sobre o conteúdo antes da leitura.

36. Fazer um esquema do texto para relacionar as informações mais importantes.

37. Copiar os trechos mais importantes do texto

38. Listar as informações que entendi com facilidade.

Você se utiliza de outras estratégias que não estão na lista acima? Se sim, registre-as a seguir.

Recebido: 30/04/2021.

Aprovado: 02/08/2021. 